\title{
What drives national adaptation? A global assessment
}

\author{
Lea Berrang-Ford • James D. Ford • \\ Alexandra Lesnikowski • Carolyn Poutiainen • \\ Magda Barrera • S. Jody Heymann
}

Received: 1 November 2013 / Accepted: 3 February 2014 / Published online: 22 March 2014

(C) The Author(s) 2014. This article is published with open access at Springerlink.com

\begin{abstract}
That the climate is changing and societies will have to adapt is now unequivocal, with adaptation becoming a core focus of climate policy. Our understanding of the challenges, needs, and opportunities for climate change adaptation has advanced significantly in recent years yet remains limited. Research has identified and theorized key determinants of adaptive capacity and barriers to adaptation, and more recently begun to track adaptation in practice. Despite this, there is negligible research investigating whether and indeed if adaptive capacity is translating into actual adaptation action. Here we test whether theorized determinants of adaptive capacity are associated with adaptation policy outcomes at the national level for 117 nations. We show that institutional capacity, in particular measures of good governance, are the strongest predictors of national adaptation policy. Adaptation at the national level is limited in countries with poor governance, and in the absence of good governance other presumed determinants of adaptive capacity show limited effect on adaptation. Our results highlight the critical importance of institutional good governance as a prerequisite for national adaptation. Other elements of theorized adaptive capacity are unlikely to be sufficient, effective, or present at the national level where national institutions and governance are poor.
\end{abstract}

Electronic supplementary material The online version of this article (doi:10.1007/s10584-014-1078-3) contains supplementary material, which is available to authorized users.

L. Berrang-Ford $(\bowtie) \cdot$ J. D. Ford $\cdot$ A. Lesnikowski $\cdot$ C. Poutiainen

Department of Geography, McGill University, 805 Sherbrooke Street Ouest, Montreal, QC H3A 0B9,

Canada

e-mail: lea.berrangford@mcgill.ca

M. Barrera · S. J. Heymann

Institute for Health and Social Policy, McGill University, Montreal, QC, Canada

Present Address:

A. Lesnikowski

School of Community and Regional Planning, The University of British Columbia, \#433-6333 Memorial

Road, Vancouver, BC V6T 1Z2, Canada

Present Address:

S. J. Heymann

UCLA Fielding School of Public Health, 650 Charles E. Young Drive S., Los Angeles, CA 90095-1772, USA 


\section{Introduction}

That the climate is changing and societies will have to adapt is now unequivocal, with adaptation becoming a core focus of climate policy (Khan and Roberts 2013). The establishment of the Green Climate Fund is expected to become an important source of adaptation finance for low and middle income countries in the coming years. Similarly, climate adaptation has been articulated as an important component of broader sustainable development goals, and has become an emerging priority in industrialized nations (Ford and Berrang-Ford 2011). As adaptation has become a core element of climate policy and funding has been mobilized, our understanding of the challenges, needs, and opportunities for adaptation has advanced but remains limited (Adger et al. 2007; IPCC 2012). There is a long history of research conceptualizing the key determinants of vulnerability and identifying predictors of adaptive capacity (Smit and Wandel 2006; Gupta et al. 2010; Brooks et al. 2005) and more recently, examining barriers to adaptation (Biesbroek et al. 2013; Moser and Ekstrom 2010; Bauer et al. 2012; Clar et al. 2013; Dow et al. 2013) and tracking adaptation planning (Lesnikowski et al. 2011, 2013, 2013; Berrang-Ford et al. 2011; Ford et al. 2011; Tompkins et al. 2010; Biesbroek et al. 2010; Gagnon-Lebrun and Agrawala 2007) and practice (Berrang-Ford et al. 2011; Ford et al. 2013; Preston et al. 2009). This research has advanced our understanding of what factors are likely to contribute to adaptive capacity. Adaptive capacity reflects the potential for adaptation; however, adaptation is neither inevitable nor automatic even where adaptive capacity is high (Eisenack and Stecker 2012; Ford and King 2013).

Despite these developments, there is limited research bridging our conceptual understanding of what constitutes adaptive capacity with measurable and documented adaptation outcomes or action. What elements of adaptive capacity are most significant in determining adaptation action? Given the magnitude of the adaptation challenge and adaptation financing committed, it is critical that theorized predictors of adaptive capacity be empirically examined to evaluate to what extent they are associated with adaptation in practice. In this study we test which factors are statistically associated with national-level adaptation, providing an assessment of the context and comparative contribution of different elements of adaptive capacity in driving adaptation actions. Our national focus reflects the importance of national governments as the central pivot for adaptation planning, determining policy priorities and distributing resources and support, with countries also a feasible unit of comparison for which systematic and standardized data are available (Gagnon-Lebrun and Agrawala 2007; Ford et al. 2013). This is, to our knowledge, the first global-scale analysis of predictors of national adaptation actions.

\section{Methods}

We systematically reviewed reporting on adaptation in 117 countries using the UNFCCC Fifth National Communications (NC5) as a proxy data source for global adaptation. We included only NCs submitted between 2008 and July 1, 2012 in our analysis in order to capture a sample of updated and temporally comparable data. Only documents available on the UNFCCC website are included, and our dataset contains 117/195 national signatories (Supp Mat). Most large global nations are included, with the notable exception of China, Venezuela, and parts of central and east Africa, and south Asia. While the NCs are an imperfect proxy for calculating the Adaptation Initiatives Index (AII), they are one of the only systematically collected data sources available to compare trends in adaptation among nations, and have been used previously to evaluate adaptation progress and highlight trends among industrialized 
nations (Lesnikowski et al. 2011, 2013; Gagnon-Lebrun and Agrawala 2007; Ford et al. 2013). The benefit of the NCs is the availability of standardized and comprehensive data for a sufficient number of countries to allow multivariate statistical analysis. Analysis using the NCs necessitates focus on national-level adaptations only, however, and is subject to bias based on reporting effort and ability among participating countries. Our data source should thus not be used to infer adaptation processes and drivers at the regional or municipal levels, for example, nor in the non-governmental or private sectors.

We use Lesnikowski et al.'s $(2013,2013)$ AII to capture national level adaptation actions among 117 nations. This index is calculated based on the type and level of adaptation actions documented in national reporting to the UNFCCC through the National Communications (NC), which we use as a proxy data source for global adaptation. We developed a codebook to extract data related to adaptation action in the NC5s (Supp Mat). As per our previous work (Lesnikowski et al. 2011, 2013), actions were differentiated by type and level of action. Groundwork level actions are those initiatives considered critical for informing and preparing for adaptation. Types of action considered to be groundwork level include impact and vulnerability assessments, adaptation research, conceptual tools, climate change scenarios, stakeholder networking, and policy recommendations. Adaptation level actions are understood as initiatives that are implemented to tangibly improve the adaptive capacity/resiliency of human and natural systems, and include organizational developments, regulations, infrastructure/technology/innovation, public awareness and outreach, surveillance and monitoring, and financial support. Adaptation actions are weighted 1 or 2 to reflect the distinction between preparatory (groundwork $=1$ ) actions and tangible actions that improve community resiliency to climate change (adaptation=2):

$$
\mathrm{AII}=\left(\mathrm{To}_{\# \mathrm{GW}} \mathrm{X} 1\right)+\left(\mathrm{ToA}_{\# \mathrm{ADAPT}} \mathrm{X} 2\right)
$$

Where:

To $A_{\# \mathrm{GW}} \quad \mathrm{N}$. of types of groundwork action (ranging from 0 to 5 types of groundwork action) To $A_{\# A D A P T}$ N. of types of adaptation action (ranging from 0 to 7 types of adaptation action, with a maximum value of 14)

The possible range of AII scores is $0-19$, with 0 representing no evidence of any response taken to climate change risks and 19 representing demonstrated response to all 12 types of action.

We selected national-level predictors of adaptation action based on theoretical and empirical evidence in the literature, and availability of standardized comparable data. We canvassed the peer-reviewed literature on adaptation, adaptive capacity and vulnerability to identify potential theorized indicators of adaptation outcomes. This review continued until saturation was achieved. Variables were selected for analysis based on level of support in the literature for the role of the variable as a measure of adaptive capacity, the relevance to our objectives and methods (national-level, potential predictors of adaptation action), availability of recent datasets, and completeness of global coverage. To frame our analysis, we organized variables within broad categories of adaptive capacity as outlined in the IPCC by Smit and Pilifosova (2001). These include economic resources, technology, information and skills, social infrastructure, institutions, and equity. We added a category for 'exposure', reflecting biophysical exposure to hazards and previous experience with extreme events. We were unable to identify appropriate measures of social infrastructure that could be systematically collected at the national level. Measures of inequality lacked a sufficient sample size of countries to be appropriately modeled, and are therefore excluded from the results presented here. We 
excluded composite vulnerability or development variables such as the Human Development Index (HDI) or the GAIN climate vulnerability index since these measures aggregate several conceptual processes and preclude comparison and consideration of the different determinants of adaptive capacity. Variables considered for analysis are summarized in Table 1.

Due to high colinearity among predictor variables, we identified a reduced set of variables for use in multivariate regression using bivariate analyses comparing all predictor variables with our Adaptation Initiative Index (AII). Variables significantly correlated with adaptation at $p<0.10$ were considered for retention. Pairs of variables within adaptive capacity categories that were strongly correlated with each other (Pearson correlation: $p>0.7$ ) were considered for elimination where the more significant variable (lowest log likelihood) was retained. All variables were checked for linear relationships with the outcome (AII) and transformed where appropriate. Variables retained for multivariate regression are highlighted in Table 1.

We cumulatively constructed a series of models to test for the relative significance of variables within our 5 categories of adaptive capacity (Models 1-5). We used general linear models (GLM) to compare model performance using the AIC, presenting both AIC and $\mathrm{R}^{2}$

Table 1 Theorized predictors of national adaptation. Detailed variable descriptions and justification for selection are provided in the Supplemental Materials

\begin{tabular}{|c|c|}
\hline Indicator & Date \\
\hline \multicolumn{2}{|l|}{ Exposure } \\
\hline a Global climate risk index (high scores reflect nations most impacted) & $1990-2008$ \\
\hline${ }^{\mathrm{a}}$ Coastal exposure (\% population, within $100 \mathrm{~km}$ of the coast) & 2000 \\
\hline \multicolumn{2}{|l|}{ Economic resources } \\
\hline${ }^{\mathrm{a}}$ Total population & 2008 \\
\hline Population density $\left(\mathrm{pp} / \mathrm{km}^{2}\right)$ & 2008 \\
\hline${ }^{\mathrm{a}} \mathrm{GDP}$ (USD) & 2008 \\
\hline GDP per capita & 2008 \\
\hline \multicolumn{2}{|l|}{ Technology } \\
\hline${ }^{\mathrm{a}}$ Internet users (per 100 people) & 2008 \\
\hline Mobile cellular subscriptions (per 100 people) & 2008 \\
\hline \multicolumn{2}{|l|}{ Information \& skills } \\
\hline 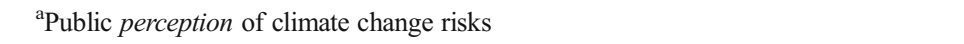 & $2007 / 2008$ \\
\hline Public awareness of climate change & $2007 / 2008$ \\
\hline${ }^{\mathrm{a}}$ Literacy rate $(>15$ years $)$ & 1999-2007 \\
\hline Public expenditure on education as \% GDP & 2008 \\
\hline \multicolumn{2}{|l|}{ Institutions } \\
\hline${ }^{a}$ Environmental sustainability index: treaty component (72) & 2004 \\
\hline${ }^{\mathrm{a}}$ Good governance (Corruption perceptions index), (lower values, higher corruption) & 2008 \\
\hline Civil liberties & 2008 \\
\hline Political rights & 2008 \\
\hline Government effectiveness & 2008 \\
\hline Voice and accountability & 2008 \\
\hline Political stability & 2008 \\
\hline Environmental Performance Index (EPI) & 2010 \\
\hline
\end{tabular}

${ }^{a}$ Variables selected for final inclusion in multivariate modeling 
values from ordinary least squares regression. We constructed a best-fit model (Model 6) based on minimization of the AIC. OLS post-estimation procedures were performed to confirm that the best-fit model was correctly specified and modeling assumptions met. Data were stored in MS Access, and all analyses were performed using STATA (StataCorp, SE 11).

\section{Results}

Results highlight a dominant role for institutional determinants of adaptive capacity in driving adaptation action: institutional variables are the strongest predictors of national adaptation score, and this was consistent regardless of model type or variable combination. Model results are presented in Table 2. The most substantive effect is observed following the introduction of institutional variables in Model 5, with the $\mathrm{R}^{2}$ increasing from 0.15 in Model 4 to 0.28 in Model 5 (and a sizeable drop in AIC). Notably, the best fit model (Model 6) retains only the institutional variables and total national population size, with these variables explaining $31 \%$ of the variation in adaptation score among global nations. In Model 6, good governance (perception of corruption) is highly significant, while both population size and the Environmental Performance Index (EPI) are significant at $p<0.05$.

The strongest and most consistent predictor of variation in national adaptation is our measure of good governance, based on Transparency International's Corruption Perceptions Index (CPI) (see maps, Supp Mat). This variable alone explains $19 \%$ of the variation in adaptation action among countries and the strength and significance of its association with adaptation is unaffected by the inclusion of any of the variables we tested. The CPI is a composite measure ranking countries based on how corrupt their public sector is perceived to be, and thus reflects a generalized measure of the quality and efficacy of governance institutions within a country. The addition of our environmental governance variables, ESI and EPI, increases our explanatory power to $28 \%$, presumably explaining the environmentally-specific governance commitment of nations. The negative coefficient for EPI in the models reflects confounding between the two environmental indices (EPI and ESI), indicating that while the ESI is capturing institutional commitment towards environmental treaties, ratification alone may result in over-prediction of actual adaptation action in the absence of effective institutional commitment to policy implementation.

In addition to the significance of institutional variables in predicting adaptation score, good governance appears to be acting as an effect modifier for the relationship between other variables and adaptation actions. In particular, the association between population and adaptation in the dataset varies depending on a country's governance capacity. This can be seen in Fig. 1, which stratifies the correlation between population and adaptation score by governance. Among countries with higher than average governance (CPI), there is a statistically significant association between population and adaptation score. Among countries with lower than average governance, however, population has no association with the adaptation score. These results indicate that the effect of a country's population size on adaptation is only significant in the presence of strong institutional capacity and governance. In fact, subset models stratified by governance (using the CPI) and excluding all institutional variables show that where institutional governance is low (i.e. lower than average), none of our predictor variables improved model fit compared to the null model. Sample sizes for subset models are too low to provide robust results, however, and are thus not presented here.

Population size is retained in the best-fit model, suggesting that more populous countries have higher capacity to implement adaptation action or policy. Notably, population size and GDP were highly collinear (Pearson's Correlation co-efficient $=0.73, p<0.01$, Supp Mat); 


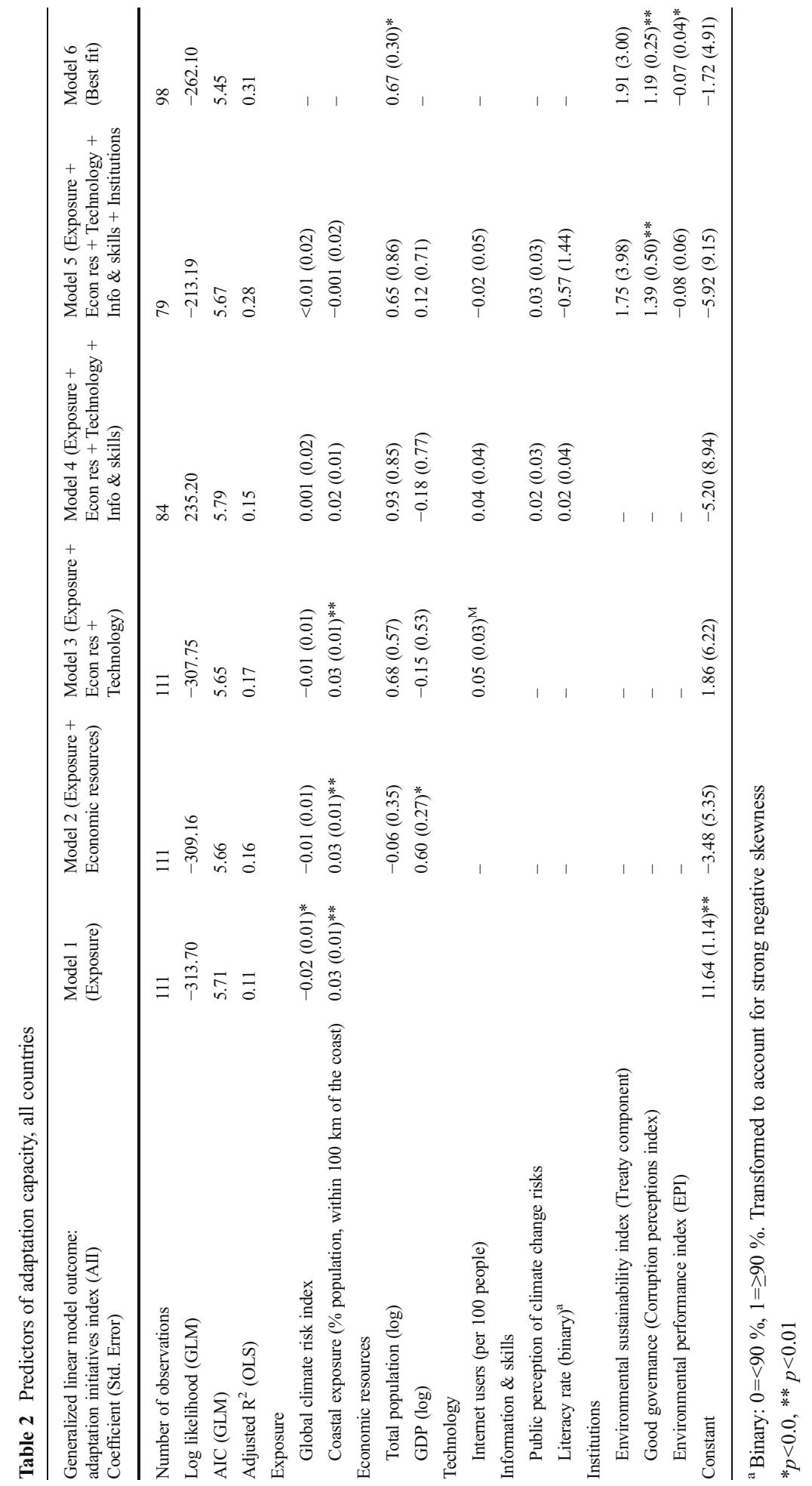




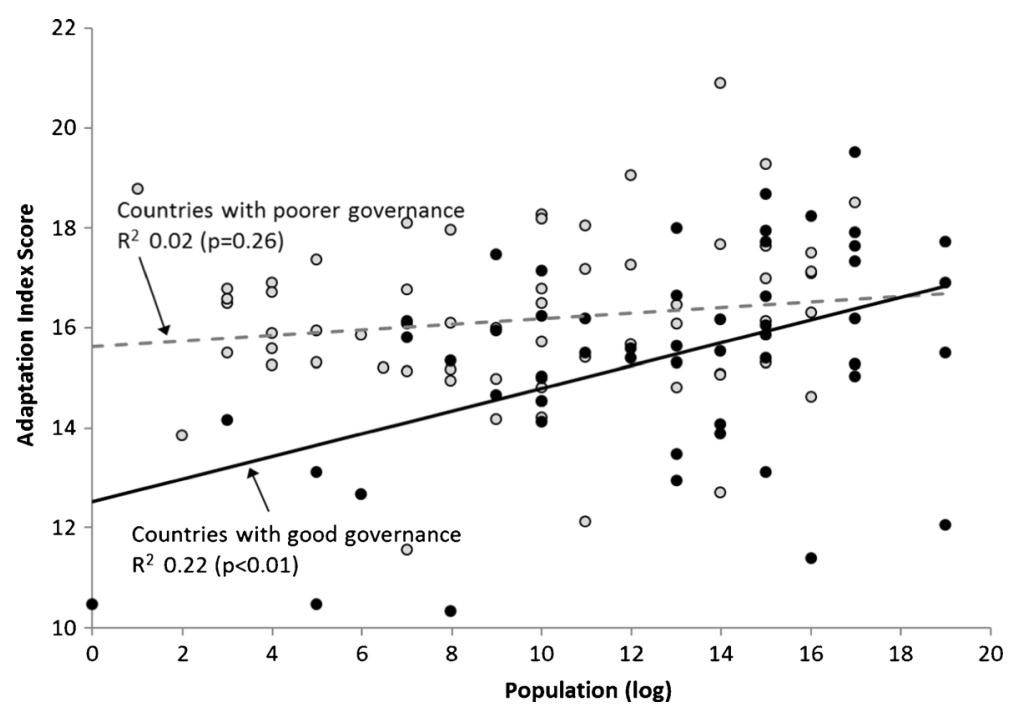

Fig. 1 Governance as an effect modifier for the effect of national total population size on adaptation score index. Countries are distinguished between those with government effectiveness above the mean CPI ('good governance', black points) or below the mean CPI ('poorer governance', grey points). Higher national population is significantly associated with higher adaptation scores for countries with good governance, but there is no association between population and adaptation score in countries with poorer governance

while population size may not necessarily imply wealth, the two variables co-vary and cannot be modeled together. Thus population size may be acting - at least statistically - as a generalized proxy for national wealth and size of national economy in the model. More populous, wealthier countries may, however, simply have better capacity to report adaptations and produce detailed UNFCCC reports. To test this, we added a proxy for reporting to the model, reporting intensity, which is based on the total number of actions (or rows) recorded in our database for each country. When reporting intensity is included, population size is no longer significant in the model. Given that total number of adaptation actions in the database may in fact reflect real adaptation activity, however, including reporting intensity in the final model risks over-fitting and is therefore not included in Table 2. It thus remains unclear whether population size and wealth contribute to more detailed and extensive reporting of adaptation or whether more populous, wealthier countries are actually engaging in more adaptation. Notably, good governance remains highly significant even when controlling for reporting. The effect of good governance on adaptation, therefore, cannot be attributed solely to more intensive or detailed reporting by nations.

Many of our predictor variables were significantly correlated with adaptation yet highly collinear with institutional variables (particularly CPI). This was particularly true for internet use. This may indicate that good governance is an antecedent variable, with governance affecting adaptation outcomes through supporting and enabling technological development. If institutional capacity is indeed a causal antecedent to other variables, other theorized predictors of adaptive capacity may thus not be insignificant, but rather more proximal drivers of adaptation. We removed institutional variables as antecedents and find that improved technology, population size and biophysical exposure variables are the most likely variables retained (model not shown). Technology arises as a likely causal pathway through which institutional capacity may facilitate adaptation. 


\section{Discussion}

We have previously assessed national-level factors associated with adaptation actions for the health sector among 38 Annex I Parties to the UNFCCC (i.e. developed nations) (Lesnikowski et al. 2013). This work highlighted national environmental governance, wealth, population size, and corruption as correlates of national adaptation outcomes among developed nations. Inference from these results, however, was limited by a small sample size that precluded multivariate analysis and comparative exploration of how determinants of adaptive capacity differentially contribute to adaptation outcomes. Here, we tested and validated the results of Lesnikowski et al. (2013) using a global dataset of 117 countries, focusing on adaptation across all sectors, and employing multivariate analysis.

Our results highlight several important implications for national and international adaptation policy and planning. The good news is that there is evidence of national adaptation action even in small nations with low national GDP (St Lucia) or GDP per capita (Rwanda, Malawi). The bad news is that global adaptation progress, financing and investment may be constrained by lack of governance capacity. Our results suggest, for example, that the importance of all other theorized determinants of national adaptive capacity may be predicated on the presence of good national governance (here proxied by low corruption). The significance of good governance held even when controlling for population size, wealth, environmental policy commitment, biophysical exposure, development indices, and reporting intensity. Secondly, elements of adaptive capacity do not act independently. Some elements, such as technology and possibly information and skills, may be intermediate mechanisms through which good governance affects national adaptation action and capacity.

Our analysis focuses on the national level, and therein reflects primarily adaptations led by national governments. What we do not know is whether nations with poor governance are simply not engaging in adaptation action, or if adaptation is occurring within other jurisdictions (e.g. municipal, regional, civil society). Research might fruitfully investigate whether and where adaptation is occurring in nations with poor governance, and whether governance is also associated with adaptation action at different scales and jurisdictions, for example at the regional and municipal levels and in the non-governmental and private sectors. The next challenge of adaptation tracking also includes consideration of adaptation effectiveness, a methodologically and conceptually tricky yet essential endeavour.

These results are consistent with a body of literature characterizing the mechanisms through which governance and institutions can enable the development of adaptation action (Gupta et al. 2010; Moser and Ekstrom 2010; Pahl-Wostl 2009; Vogel et al. 2007; Dovers and Hezri 2010; McDonald 2011). Moser (2010), for example, describes institutional infrastructure and good governance as necessary for effective problem detection, information gathering, assessment of adaptation options, transmission and communication of information to increase awareness and understanding, and engagement of key stakeholders. Gupta et al. (2010) similarly identify dimensions of adaptive capacity, many of which - trust, access to information, legitimacy, and accountability, for example - are embedded within institutional governance structures that can promote or impede adaption. The surprise here is not that good governance promotes adaptation - this has been well-recognized and described in the qualitative literature for some time - but rather the magnitude and dominance of governance as a predictor of national adaptation action. Our results suggest that governance may be acting as a more causally distal determinant of other more proximal drivers of adaptation, notably technology and possibly also information and skills.

Where governance is poor, yet vulnerability is high, adaptation planning and financing should focus on promotion and development of good governance. Notably, many of the 
world's most vulnerable nations also have poor governance. Given financing commitments to support adaptation in low-income nations through the UNFCCC, our results have significant implications regarding the importance of the readiness of nations to effectively implement adaptation, and highlight the critical value of focusing national adaptation planning on building governance and adaptive capacity.

Acknowledgments This work was supported by the Social Sciences and Humanities Research Council of Canada. We thank two anonymous reviewers who provided constructive comments.

Open Access This article is distributed under the terms of the Creative Commons Attribution License which permits any use, distribution, and reproduction in any medium, provided the original author(s) and the source are credited.

\section{References}

Adger WN et al (2007) In: Parry ML et al. (eds) Climate change 2007: impacts, adaptation and vulnerability. Contribution of Working Group II to the Fourth Assessment Report of the Intergovernmental Panel on Climate Change 717-743. Cambridge University Press

Bauer A, Feichtinger J, Steurer R (2012) The governance of climate change adaptation in 10 OECD countries: challenges and approaches. J Environ Policy Plann 14. doi:10.1080/1523908x.2012.707406

Berrang-Ford L, Ford JD, Paterson J (2011) Are we adapting to climate change? Glob Environ Chang Hum Policy Dimens 21:25-33. doi:10.1016/j.gloenvcha.2010.09.012

Biesbroek GR et al (2010) Europe adapts to climate change - comparing national adaptation strategies. Glob Environ Chang 20:440-450

Biesbroek GR, Klostermann JEM, Termeer CJAM, Kabat P (2013) On the nature of barriers to climate change adaptation. Regional Environmental Change Published on-line ahead of print

Brooks N, Adger WN, Kelly PM (2005) The determinants of vulnerability and adaptive capacity at the national level and the implications for adaptation. Glob Environ Chang Hum Policy Dimens 15:151-163. doi:10. 1016/j.gloenvcha.2004.12.006

Clar C, Prutsch A, Steurer R (2013) Barriers and guidelines for public policies on climate change adaptation: a missed opportunity of scientific knowledge-brokerage. Nat Res Forum 37:1-18. doi:10.1111/1477-8947.12013

Dovers SR, Hezri AA (2010) Institutions and policy processes: the means to the ends of adaptation. Wiley Interdiscip Rev Clim Chang 1:212-231. doi:10.1002/wcc.29

Dow K et al (2013) COMMENTARY: limits to adaptation. Nat Clim Chang 3:305-307

Eisenack K, Stecker R (2012) A framework for analyzing climate change adaptations as actions. Mitig Adapt Strateg Glob Chang 17:243-260. doi:10.1007/s11027-011-9323-9

Ford, JD, King D (2013) A framework for examining adaptation readiness. Mitigation and Adaptation Strategies for Global Change. doi:10.1007/s11027-013-9505-8

Ford JD, Berrang-Ford L, Lesnikowski A, Barrera M, Heymann SJ. (2013) How to track adaptation to climate change: a typology of approaches for national-level application. Ecology and Society 18(3):40

Ford JD, Berrang-Ford L (2011) Climate change adaptation in developed nations: from theory to practice. Springer

Ford JD, Berrang-Ford L, Patterson J (2011) A systematic review of observed climate change adaptation in developed nations. Clim Chang Lett. doi:10.1007/s10584-011-0045-5

Gagnon-Lebrun F, Agrawala S (2007) Implementing adaptation in developed countries: an analysis of progress and trends. Clim Pol 7:392-408

Gupta J et al (2010) The adaptive capacity wheel: a method to assess the inherent characteristics of institutions to enable the adaptive capacity of society. Environ Sci Pol 13:459-471. doi:10.1016/j.envsci.2010.05.006

IPCC (2012) Managing the risks of extreme events and disasters to advance climate change adaptation. A special report of working groups I and II of the intergovernmental panel on climate change. Cambridge University Press, Cambridge, $582 \mathrm{pp}$

Khan MR, Roberts JT (2013) Adaptation and international climate policy. Wiley Interdiscip Rev Clim Chang 4: 171-189. doi:10.1002/wcc. 212

Lesnikowski AC et al. (2011) Adapting to the health impacts of climate change: a study of UNFCCC Annex I parties. Environ Res Lett 6. doi:10.1088/1748-9326/6/4/044009

Lesnikowski A et al. (2013) National-level factors affecting planned, public adaptation to health impacts of climate change. Glob Environ Chang 23:1153-1163. 
Lesnikowskiw AC, Ford JD, Berrang-Ford L, Barrera M, Heymann J (2013) How are we adapting to climate change? A global assessment. Mitigation and Adaptation Strategies for Global Change. doi:10.1007/s11027013-9491-X

McDonald J (2011) The role of law in adapting to climate change. Wiley Interdiscip Rev Clim Chang 2:283-295. doi: $10.1002 /$ wcc. 96

Moser SC, Ekstrom JA (2010) A framework to diagnose barriers to climate change adaptation. Proc Natl Acad Sci U S A 107:22026-22031. doi:10.1073/pnas.1007887107

Pahl-Wostl C (2009) A conceptual framework for analysing adaptive capacity and multi-level learning processes in resource governance regimes. Glob Environ Chang Hum Policy Dimens 19:354-365. doi:10.1016/j. gloenvcha.2009.06.001

Preston B, Westaway R, Dessai S, Smith T (2009) CSIRO Publishing

Smit B, Pilifosova O (2001) Adaptation to climate change in the context of sustainable development and equity. In: McCarthy JJ, Canzianni OF, Leary NA, Dokken DJ, White KS (eds) Climate Change 2001: Impacts, Adaptation, and Vulnerability - Contribution of Working Group II to the Third Assessment Report of the Intergovernmental Panel on Climate Change. Cambridge University Press.

Smit B, Wandel J (2006) Adaptation, adaptive capacity, and vulnerability. Glob Environ Chang 16:282-292

Tompkins EL et al. (2010) Observed adaptation to climate change: UK evidence of transition to a well-adapting society. Glob Environ Chang Hum Policy Dimens 20. doi:10.1016/j.gloenvcha.2010.05.001

Vogel C, Moser SC, Kasperson RE, Dabelko GD (2007) Linking vulnerability, adaptation, and resilience science to practice: pathways, players, and partnerships. Glob Environ Chang Hum Policy Dimens 17:349-364. doi: 10.1016/j.gloenvcha.2007.05.002 